\title{
DISEÑOS DE PUNTAS DE PROYECTIL EN EL VALLE DE SANTA MARÍA (CATAMARCA, ARGENTINA): UNA APROXIMACIÓN A LA OCUPACIÓN CAZADORA - RECOLECTORA
}

\author{
PROJECTILE POINT DESIGNS IN THE SANTA MARÍA VALLEY (CATAMARCA, \\ ARGENTINA): AN APPROACH TO THE HUNTER - GATHERER OCCUPATION
}

\author{
Agustin Agnolin ${ }^{1}$ y Juan Pablo Carbonelli ${ }^{2}$
}

\begin{abstract}
En este trabajo presentamos el análisis técnico-morfológico y de diseño efectuado sobre 200 cabezales líticos pertenecientes a colecciones de museos y recolecciones de superficie del valle de Santa María, Catamarca. En total se identificaron 10 tipos morfológicos, los cuales han sido reconocidos para la región de Puna, específicamente para la microrregión de Antofagasta de la Sierra. Como dichos tipos morfológicos se circunscriben a marcos temporales específicos a partir de la coincidencia en el diseño con los especímenes analizados por nosotros, es factible inferir la ocupación cazadora-recolectora en el valle de Santa María desde por lo menos el Holoceno Temprano. Esto se visibiliza aún más al analizar la modalidad de producción y al observar en los especímenes, fracturas en el limbo originadas por el uso. La circulación de materias primas entre puna y valles se evidencia en los cabezales líticos pertenecientes a momentos de transición hacia un modo de vida agrícola-pastoril con la incorporación de la obsidiana.
\end{abstract}

Palabras claves: valle de Santa María, cabezales líticos, colecciones de Museos, recolecciones superficiales.

In this paper, we present the techno-morphological and design analysis carried out on 200 lithic points belonging to both museum and surface collections from the Santa María Valley, Catamarca province, Argentina. A total of 10 morphological types, which have been recognized for the Puna region, specifically for the micro-region of Antofagasta de la Sierra, were identified. As such, morphological types are limited to specific time frames, based on the coincidence in design with the specimens analyzed it is possible to infer hunter-gatherer occupation in the Santa María Valley since at least the early Holocene. This becomes even more evident when analyzing the production method and observing the fractures caused by use in the edge of available specimens. The circulation of raw materials between highlands and valleys is evidenced in the lithic points corresponding to moments of transition to an agricultural-pastoral life with the addition of obsidian.

Key words: Santa María valley, lithic points, Museum collections, surface collections.

En este trabajo buscamos arrojar nuevos datos sobre las ocupaciones prehispánicas en el valle de Santa María (Catamarca) a través del estudio del diseño y producción de los cabezales líticos. Estos provienen tanto de recolecciones sistemáticas efectuadas en las localidades de Caspinchango, Andalhuala y Ampajango como de colecciones privadas.

El objetivo principal es mostrar la variabilidad existente en cabezales líticos. Asimismo, nos proponemos asignar tentativamente una cronología a los mismos, en base a la comparación con tipos morfológicos ya definidos para las regiones de Antofagasta de la Sierra (Catamarca) (Hocsman 2006; Martínez 2003), Antofalla (Catamarca) (Moreno
2010), puna de Salta (López y Restifo 2017) y Jujuy (Hoguin 2014; Restifo y Hoguin 2012) y el norte de Chile (Núñez y Santoro 1988). La justificación de este procedimiento se basa en que estas regiones poseen una cronología asociada a los diseños de cabezales líticos. Asimismo, existen indicios las mismas de contactos con las tierras bajas y las valles mesotermales desde las primeras ocupaciones humanas (Aschero 1994; Hocsman 2006; Lavallé 2000; Núñez y Santoro 1988; Yacobaccio 1991). De esta manera, empleamos este marco cronológico como referencia para nuestro objeto de estudio.

El análisis técnico-morfológico de las piezas nos permitió, en algunos casos, distinguir modalidades

\footnotetext{
CONICET, Instituto Nacional de Antropología y Pensamiento Latinoamericano (INAPL), 3 de febrero 1378 (CPC 1426 BJN), Buenos Aires, Argentina. agusagnolin@yahoo.com.ar

2 CONICET, Instituto de las Culturas (IDECU), Universidad de Buenos Aires, Facultad de Filosofía y Letras, Museo Etnográfico, Moreno 350 (CP 1091), Buenos Aires, Argentina. juanp.carbonelli@ gmail.com
}

Recibido: diciembre de 2016. Aceptado: noviembre 2017. 
de producción y discutir el uso de las materias primas. En base a estas dos herramientas, ampliaremos la información existente sobre ocupaciones cazadorasrecolectoras en el valle de Santa María, donde hasta el momento solo teníamos información de sitios de superficie cantera-taller (Carbonelli 2013).

\section{Antecedentes}

Las primeras investigaciones efectuadas con el afán de distinguir ocupaciones cazadoras-recolectoras en el valle corresponden al equipo liderado por Eduardo Cigliano, proveniente de la Universidad Nacional del Litoral. Las prospecciones efectuadas en la localidad de Ampajango permitieron definir una industria artefactual, a partir de los materiales hallados en una cantera-taller. Estos consistían principalmente en numerosos bifaces, seguidos en frecuencia por unifaces, raspadores y raederas, los cuales fueron asignados a una "cultura" de cazadores recolectores que habría ocupado la región desde hace al menos diez mil años (Cigliano 1961).

Un dato saliente de estas investigaciones es el hallazgo, en las terrazas superiores contiguas a la cantera-taller, de puntas foliáceas confeccionadas mediante talla bifacial a percusión (Cigliano1961; Cigliano et al. 1962). Por su manufactura, fueron consideradas pertenecientes a una cultura posterior al Ampajanguense, siendo asignadas a la cultura Ayampitín. Dicho planteo fue replicado por otro investigador, Delfor Chiappe, quien observó la misma asociación de bifaces y puntas lanceoladas en Entre Ríos, otro sitio del valle de Santa María (Chiappe 1967). En ambos casos las puntas correspondían en su diseño y morfología a las piezas definidas anteriormente por González (1952). Este autor definió las mismas en base primeramente a un sitio de superficie con abundantes cabezales líticos bifaciales lanceolados, de tamaño mediano y grande, espesos (Figura 1). Posteriormente encontró los cabezales líticos de este tipo en estratigrafía en la gruta de Intihuasi, obteniendo un fechado de 8068 años a.p. en niveles asociados a los mismos (González 1960).

Precisamente, Rex González había registrado una apreciable cantidad de puntas de proyectil Ayampitín procedentes del valle de Santa María y que se encontraban en colecciones del Museo de La Plata y del Instituto de Antropología de la Universidad Nacional de Tucumán (localidad Fuerte Quemado). En el caso del Museo de Ciencias Naturales de La Plata se trata de las colecciones Methffesel, Lafone Quevedo, Moreno $\mathrm{N}^{\mathrm{o}} 1$ y $\mathrm{N}^{\mathrm{o}}$ 2, Vázquez y Muñiz Barreto (localidad Caspinchango) (González 1952).

Ampliando el espacio de la investigación, Márquez Miranda y Cigliano (1961) destacan el hallazgo de tres fragmentos de puntas precerámicas "del tipo Ayampitín" en el yacimiento de la Falda del Cerro del Ingenio del Arenal (Catamarca) y de otras dos en el sitio Ingenio del Arenal Médanos (Catamarca), ambos pertenecientes al período Formativo y ubicados en los alrededores del Campo del Arenal, en el extremo sur del valle del Santa María. En consonancia con estos hallazgos, Serrano (1968) presenta una sistematización del período "precerámico" de ocupación del valle de Santa María. Como parte del mismo plantea la existencia de una serie de "culturas precerámicas" en el valle, las cuales reconoce como Ayampitín, Ampajango, Cachipampa y El Barrealito, todas ellas definidas en base a la existencia de diferentes variedades de puntas de proyectil que se sucederían cronológicamente.

También encontramos descripciones de dichos cabezales líticos en el valle Calchaquí Norte (Salta). Tarragó y de Lorenzi (1976) mencionan la presencia de éstos en dos sitios SSalCac 7 (Quipón 2) y SSalCac 13 (Agua de los Loros). Las autoras consideran a los cabezales como pertenecientes a la tradición Ayampitín, si bien destacan su variabilidad.

Debemos mencionar que aún hoy en día, los cabezales líticos siguen siendo utilizados como marcadores cronológicos en espacios vecinos. En Campo Blanco, un sitio a cielo abierto ubicado en la Quebrada de Amaicha (Tucumán), Hocsman et al. (2003) describen dentro
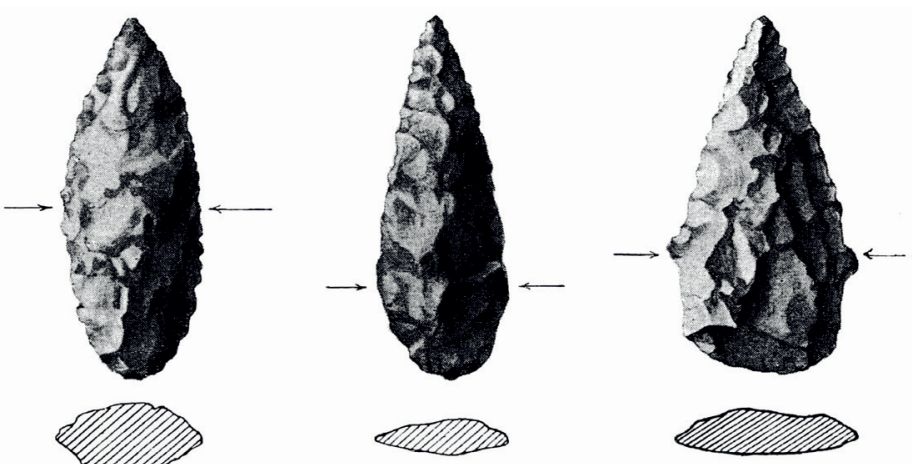

Figura 1. Puntas Ayampitín ilustradas por González (1952). Imagen tomada y modificada de González (1952). Ayampitín points drawn by González (1952). Image taken and modified from González (1952). 
del conjunto lítico, diseños artefactuales pertenecientes a momentos cronológicos anteriores a la etapa agroalfarera: puntas de proyectil triangulares apedunculadas comparables a las halladas en Inca Cueva 4 , en la puna de Jujuy (Aschero 1984) y puntas de proyectil lanceoladas como las de Peñas Chicas 1, en la puna de Catamarca (Olivera 1991), lo cual nos inclina a sugerir la posibilidad de una cronología del Holoceno Temprano y medio para el sitio.

La aparición de cabezales líticos de morfologías comparables se hace extensiva a los hallazgos situados en la Quebrada de Los Corrales, en El Infiernillo, Tucumán. Allí, el sitio Taller Puesto Viejo 1 cuenta con una secuencia estratigráfica de larga duración y fue definido como una base residencial, con áreas de actividad de manufactura y mantenimiento de instrumentos y cuenta con una datación radiocarbónica en la capa más antigua de las excavaciones, de $7420 \pm 25$ años a.p., la que se constituye como el registro radiocarbónico más antiguo por fuera de la Puna (Martínez et al. 2011, 2013)1.

Este cúmulo de investigaciones, tanto en el valle de Santa María como en sus cercanías (valle Calchaquí Norte, Quebrada de los Corrales, Figura 2) da cuenta de la existencia de poblaciones cazadoras-recolectoras en la zona de valles y aledaños, desde por lo menos el Holoceno Medio. La historia de dichas ocupaciones es hasta el momento fragmentaria, caracterizada en gran parte por hallazgos de superficie y una marcada escasez de sitios estratificados con fechados radiocarbónicos. No obstante, en este trabajo nos proponemos ubicar el material analizado en un marco cronológico tentativo construido a partir de la comparación con diseños de cabezales líticos en contextos datados de regiones adyacentes. A continuación describiremos el marco geográfico y el escenario paleoambiental en el que se pudieron haber desarrollado estas ocupaciones.

\section{Escenario Paleoclimático}

ElvalledeSantaMaríao Yocavil(Figura3) seencuentra localizado en el sector norte de las Sierras Pampeanas, ocupando el extremo nor-oriental de la provincia de Catamarca (Departamento de Santa María) y el ángulo noroeste de la provincia de Tucumán (Departamento de Tafí). Conforma una depresión tectónica en el sentido SSE-NNW de más de 100 km de extensión y cerca de los $20 \mathrm{~km}$ de ancho (Bossi et al. 2001). Es atravesado por el meridiano de $66^{\circ}$ al norte y al sur limita con los paralelos $26^{\circ}$ y $27^{\circ}$. El valle está limitado hacia el oeste por las Sierras del Cajón, al este por las sierras del Aconquija y en su extremo sur con el valle de Cajón. Las condiciones climáticas actuales del valle se enmarcan dentro de los ambientes áridos a semiáridos.

La información paleoclimática disponible hasta el momento para el Holoceno en lo que respecta a los valles mesotermales es fragmentaria. No obstante, las

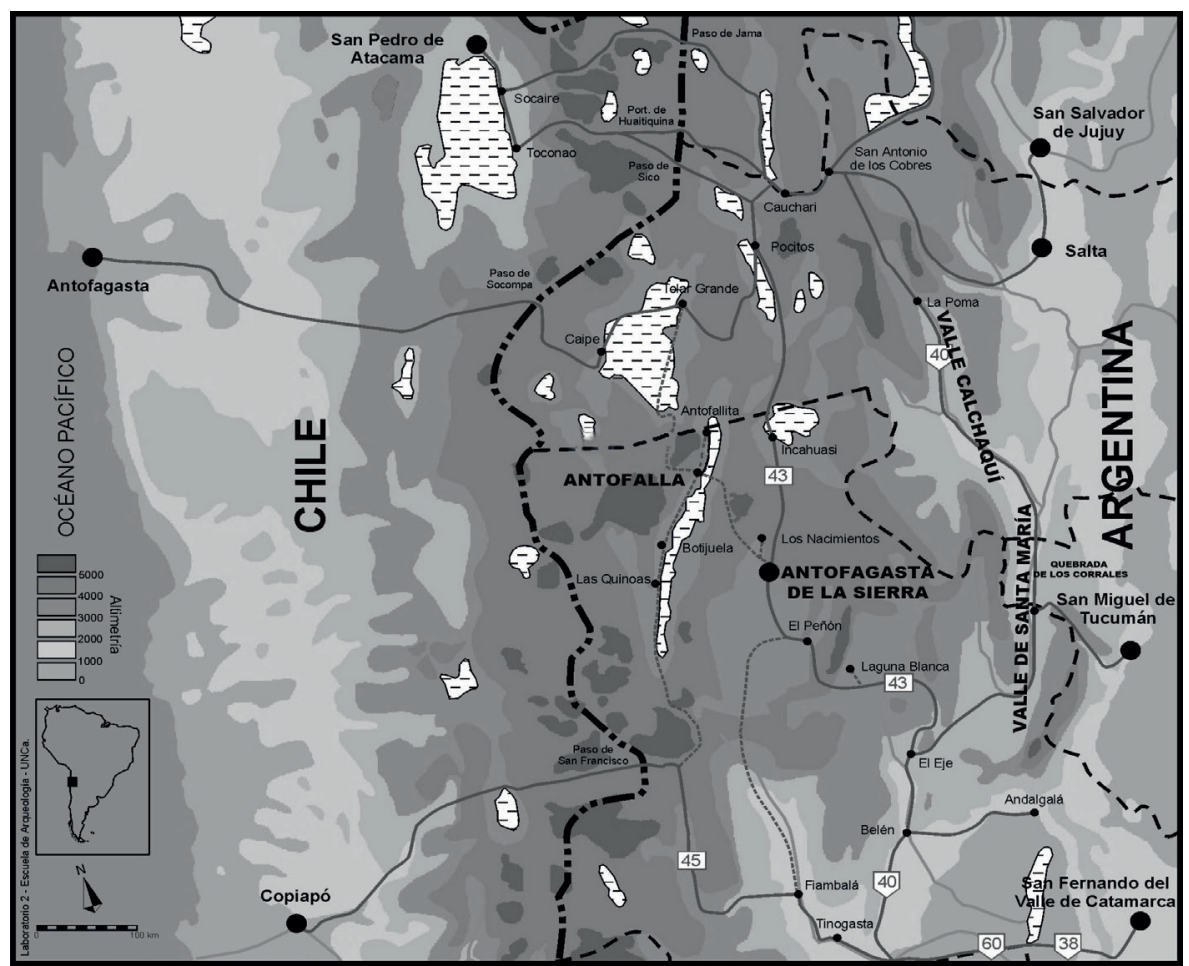

Figura 2. Ubicación de las regiones tratadas en el texto, tomado y modificado de Haber (1999). Location of regions discussed in the text, taken and modified from Haber (1999). 

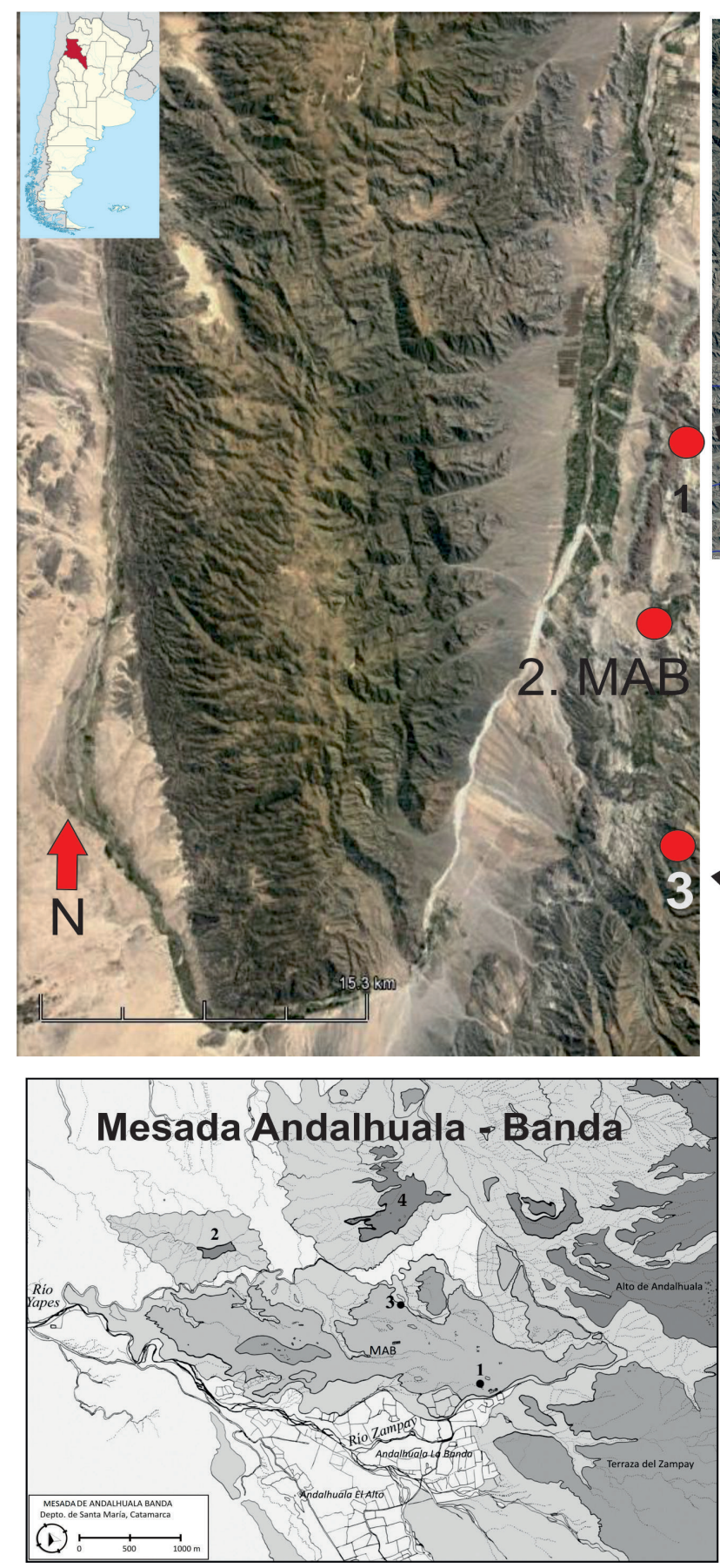
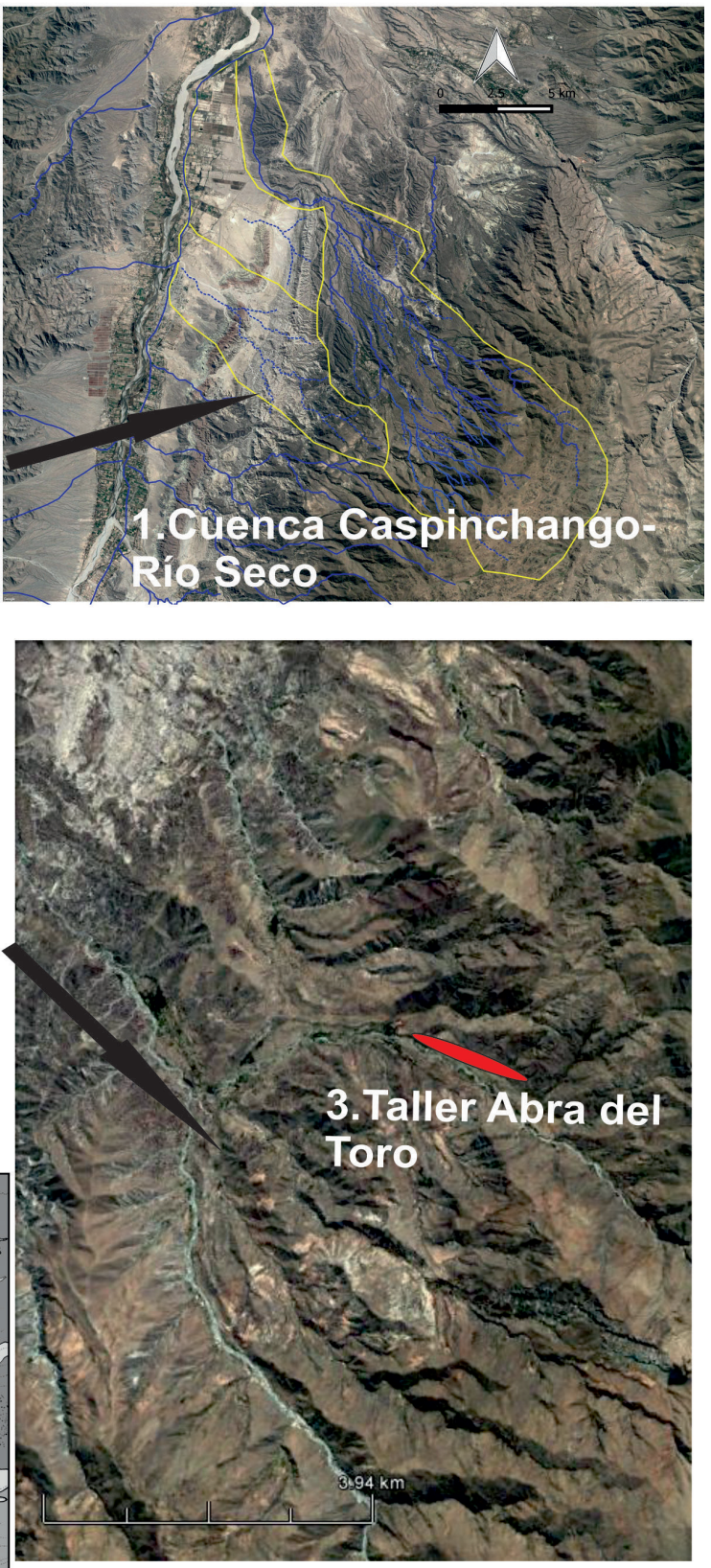

Figura 3. Ubicación del valle de Santa María. Localización de las áreas donde se recolectó material de superficie. El número 1 señala la cuenca del río Caspinchango y el río Seco, el número 2 indica la Mesada de Andalhuala Banda y el número 3 la localización del Taller Abra del Toro. Imágenes tomadas y modificadas de Lanzelotti (2012) y Álvarez Larraín (2010).

Location of the Santa María Valley. Location of the areas where surface material was collected. Number 1 indicates the basin of the Caspinchango River and the Seco River, number 2 indicates the Mesada de Andalhuala Banda and; number 3 the location of the Abra del Toro Workshop. Images taken and modified from Lanzelotti (2012) and Álvarez Larraín (2010). 
investigaciones efectuadas por el Centro de Investigaciones de Regiones Secas (CERS) se especializaron en el estudio de un tipo de rock coating que se encuentra presente en los sitios cantera-taller del valle de Santa María, como Ampajango. Al respecto, Durando et al. (1986) sostuvieron que las condiciones climáticas que posibilitaron el desarrollo de dicho barniz fueron más benignas que las actuales, antes que se iniciara el proceso de desertización. De este modo, a mediados del Holoceno y coincidiendo con el Óptimo Climático, las precipitaciones en la región (Amaicha del Valle) habrían sido mayores a las actuales. Asimismo, Somonte y Baied (2013) y Carbonelli (2013) han continuado con dicha línea de investigación en los sitios Los Bordos (Carbonelli 2013) y Planchada La Puntilla 1 y 2 (Somonte 2009), efectuando dataciones por microlaminaciones del barniz (VML), que no sólo informan acerca del fechado de la capa más antigua de esta pátina, sino de todos los eventos climáticos observados en esa microlaminación. El registro de los eventos húmedos más antiguos (WH10 y WH9) señala condiciones de humedad y bajas temperaturas a comienzos del Holoceno, seguido por un aumento de la temperatura hacia el Holoceno Medio. En lo que respecta al Holoceno Tardío, podemos mencionar la evidencia de una tendencia hacia un proceso de creciente aridización (Gómez Augier y Caria 2012; Sampietro Vattuone y Neder 2011; Strecker 1987).

A manera de síntesis, podemos señalar la existencia, en el valle de Santa María, de períodos de humedad, los cuales alternaron con períodos de mayor aridez.

\section{Procedencia de las Muestras}

Las muestras de cabezales líticos que analizaremos en este trabajo provienen de dos fuentes: recolecciones de superficie y materiales provenientes de colecciones. La consideración de los cabezales líticos provenientes de fuentes diversas integradas en un bloque homogéneo responde anuestroobjetivo principal que es el de caracterizar la diversidad de diseños de la región de estudio. Si bien entendemos que tanto las recolecciones obtenidas por nosotros como las provenientes de colecciones de museo poseen diferentes sesgos, consideramos que la pregunta que guía este trabajo no se ve afectada los mismos (Pérez de Micou 1998). Esto se debe a que nuestro principal interés es la variabilidad morfológica y las características técnicas morfológicas de las piezas, las cuales, entendemos, no se ven fuertemente afectadas por las prácticas de recolección diferenciales.

En el caso de las recolecciones de superficie, se recolectaron cabezales líticos en tres sectores del valle de Santa María (Figura 2): (1) la cuenca del río Caspinchango y el río Seco, trabajadas por Lanzelotti (2012), (2) la mesada de Andalhuala-Banda y, (3) el Abra del Toro (Ampajango), estas últimas abordadas por uno de los autores (Carbonelli 2013).
El objetivo de las prospecciones en los sectores mencionados fue obtener datos sobre diseños de artefactos que podrían contribuir a definir una cronología de las ocupaciones. En el caso de las cuencas del río Caspinchango y del río Seco, Lanzelotti (2012) efectuó 18 transectas pedestres, las cuales surgieron de un trabajo de teledetección previo y obedecieron a una estratificación del terreno que luego desarrollaremos. Por otro lado, en los casos de la terraza de Andalhuala y el Abra del Toro se llevaron a cabo cinco transectas lineales de $200 \mathrm{~m}$ de largo, con un ancho de $10 \mathrm{~m}$, barridas por tres personas cada una. En dichas transectas, se recolectó la totalidad del material observado durante los barridos.

\section{Recolecciones superficiales: cuenca del río Caspinchango y el río Seco}

Se recorrió una franja transversal al valle de Santa María sobre su margen derecha. Dicha franja está conformada por las cuencas del río Caspinchango y río Seco, los escurrimientos menores que desaguan en el río Santa María y los que se ubican entre ambas cuencas.

Lanzelotti (2012) segmentó el área de estudio en distintas unidades geomorfológicas: cordón montañoso, terrazas de piedemonte y cerros bajos, tierras malas y fondo del valle. Las transectas mencionadas anteriormente fueron concebidas para recorrer cada una de las subdivisiones de las cuencas (Lanzelotti 2012). Es en los sectores de terrazas de piedemonte y cerros bajos, donde se encontraron la totalidad de las puntas de proyectil $(\mathrm{N}=6)$.

\section{Recolecciones superficiales: Mesada de Andalhuala- Banda y Abra del Toro}

La Mesada de Andalhuala-Banda se encuentra situada en la localidad arqueológica homónima, a 25 $\mathrm{km}$ al sudeste de la ciudad de Santa María. Esta área de ocupación arqueológica abarca 186,3 ha y se encuentra ubicada entre los 2.100 y 2.300 msm (Álvarez Larraín y Lanzelotti 2013). A partir de los trabajos de teledetección y prospección pedestre llevados a cabo por Álvarez Larraín (2010) se constató que la mesada de AndalhualaBanda presenta un complejo palimpsesto de ocupaciones, atestiguado por numerosos vestigios arquitectónicos. Entre los vestigios de dichos palimpsestos se hallaron los cabezales líticos que se incluyen en este trabajo $(\mathrm{N}=16)$.

En el caso del Abra del Toro, la misma es una vía natural que comunica el valle de Santa María con el Aconquija, zona de tránsito del ganado actual y factiblemente de poblaciones prehispánicas. La recolección se efectuó sobre un glacis donde se emplaza un taller, en el que además de abundar cabezales líticos $(\mathrm{N}=52)$, existen preformas bifaciales y nódulos que habrían funcionado como reserva de materia prima. 
Tabla 1. Cronología y dispersión de los tipos morfológicos. Chronology and dispersion of morphological types.

\begin{tabular}{|c|c|c|c|c|}
\hline $\begin{array}{c}\text { Grupo } \\
\text { morfológico }\end{array}$ & Denominación & Esquema & $\begin{array}{c}\text { Cronología } \\
\text { (años a.p.) }\end{array}$ & Dispersión \\
\hline ICc4/QSA & $\begin{array}{l}\text { Punta de proyectil } \\
\text { apedunculada de limbo } \\
\text { triangular } \\
\text { (Aschero 1984). }\end{array}$ & & 10.800 a 8.000 & $\begin{array}{l}\text { Norte de Chile, } \\
\text { Antofagasta de la } \\
\text { Sierra, puna de } \\
\text { Jujuy, puna de Salta, } \\
\text { Chaschuil, valle de } \\
\text { Santa María, norte } \\
\text { de San Juan }\end{array}$ \\
\hline $\begin{array}{l}\text { PCzA - } \\
\text { Ayampitín }\end{array}$ & $\begin{array}{l}\text { Punta de proyectil } \\
\text { apedunculada. Forma } \\
\text { geométrica del contorno } \\
\text { lanceolado. } \\
\text { Forma de la base } \\
\text { convexilínea semicircular } \\
\text { (González 1952) } \\
\text { (Martínez 2003). }\end{array}$ & $\Lambda$ & 8.600 a 3.400 & $\begin{array}{l}\text { Antofagasta de la } \\
\text { Sierra, Chaschuil, } \\
\text { región serrana de } \\
\text { Córdoba, San Luis, } \\
\text { norte de Chile, puna } \\
\text { de Jujuy, puna de } \\
\text { Salta, Catamarca, La } \\
\text { Rioja y San Juan }\end{array}$ \\
\hline
\end{tabular}

\begin{tabular}{lll}
\hline & $\begin{array}{l}\text { Puntas de proyectil } \\
\text { pedunculadas, aletas } \\
\text { entrantes rectas u obtusas. } \\
\text { Limbo lanceolado o } \\
\text { triangular (Martínez 2003). }\end{array}$ & $\begin{array}{l}\text { Antofagasta de la } \\
\text { Sierra, Antofalla }\end{array}$ \\
\end{tabular}

\begin{tabular}{|c|c|c|c|}
\hline QSF & $\begin{array}{l}\text { Punta de proyectil destacado } \\
\text { y hombros o esbozado. } \\
\text { Limbo triangular de bordes } \\
\text { rectos } \\
\text { (Aschero et al. 1991). }\end{array}$ & 6.500 a 4.000 & $\begin{array}{l}\text { Antofagasta de la } \\
\text { Sierra, puna de Salta, } \\
\text { puna de Jujuy }\end{array}$ \\
\hline PPB & $\begin{array}{l}\text { Punta de proyectil con } \\
\text { pedúnculo destacado y } \\
\text { hombros. } \\
\text { Limbo triangular de bordes } \\
\text { convexos } \\
\text { (Hocsman 2006). }\end{array}$ & 5.400 a 3.400 & $\begin{array}{l}\text { Antofagasta de la } \\
\text { Sierra }\end{array}$ \\
\hline $\mathrm{PChF}$ & $\begin{array}{l}\text { Punta de proyectil } \\
\text { apedunculada. Forma } \\
\text { geométrica del contorno } \\
\text { lanceolada de bordes } \\
\text { subparalelos (Hocsman } \\
\text { 2006). }\end{array}$ & 5.400 a 3.400 & $\begin{array}{l}\text { Antofagasta de la } \\
\text { Sierra }\end{array}$ \\
\hline $\mathrm{PChE}$ & $\begin{array}{l}\text { Punta de proyectil } \\
\text { apedunculada } \\
\text { Forma geométrica del } \\
\text { contorno lanceolada } \\
\text { (Hocsman 2006). }\end{array}$ & 4.800 a 2.900 & $\begin{array}{l}\text { Norte de Chile, puna } \\
\text { de Jujuy, Antofagasta } \\
\text { de la Sierra }\end{array}$ \\
\hline $\mathrm{PChB}$ & $\begin{array}{l}\text { Punta de proyectil con } \\
\text { pedúnculo destacado y aletas } \\
\text { entrantes. Limbo lanceolado } \\
\text { o triangular de bordes } \\
\text { convexos (Hocsman 2006). }\end{array}$ & 4.100 a 3.400 & $\begin{array}{l}\text { Antofagasta de la } \\
\text { Sierra, puna de Jujuy }\end{array}$ \\
\hline PPC & $\begin{array}{l}\text { Punta de proyectil con } \\
\text { pedúnculo destacado y aletas } \\
\text { entrantes rectas u obtusas } \\
\text { o aletas y hombro. Limbo } \\
\text { lanceolado o triangular de } \\
\text { bordes convexos o rectos } \\
\text { (Hocsman 2006). }\end{array}$ & 4.000 a 3.000 & $\begin{array}{l}\text { Puna de Jujuy, } \\
\text { Antofagasta de la } \\
\text { Sierra, norte de } \\
\text { Chile, Chaschuil }\end{array}$ \\
\hline
\end{tabular}




\section{Material proveniente de colecciones}

En segundo lugar, nuestra muestra de cabezales líticos incluye también piezas provenientes de tres colecciones alojadas en museos:

(a) Una colección privada que se encuentra en la Fundación Félix de Azara en Buenos Aires. En este caso, solo sabemos que las piezas $(\mathrm{N}=22)$ remiten a un sector indefinido del valle de Santa María.

(b) Las colecciones Zavaleta, Salvatierra y Schreiter que se encuentran en el Museo Etnográfico Juan Bautista Ambrosetti (UBA) $(\mathrm{N}=38)$. Al igual que en el caso anterior las piezas tienen como procedencia el valle de Santa María sin mayores precisiones.

(c) Las colecciones Methfessel, Moreno, Muñiz Barreto y Lafone Quevedo, las cuales se encuentran en la División de Arqueología del Museo de La Plata, Facultad de Ciencias Naturales y Museo, Universidad Nacional de La Plata $(\mathrm{N}=65)$. Estas colecciones presentan un carácter particular dado que conforman las principales evidencias sobre las cuales se basó inicialmente la hipótesis de una ocupación cazadora-recolectora de los valles (González 1952). Al igual que en los casos anteriores, la única procedencia indicada es valle de Santa María.

\section{Metodología}

El análisis de los cabezales líticos se concentrará en tres aspectos principales: el diseño, el proceso de producción (en el caso que sea factible reconocerlo) y las materias primas. Con respecto al primer punto, Nelson (1997) se refiere al diseño como una selección de variables que realiza el tallador para destinar la pieza a una función específica. Por lo tanto, en el diseño se encuentra implícito el proceso y el conocimiento básico para producir instrumentos. En el caso concreto del noroeste argentino (NOA), el análisis tecno-morfológico de una serie de piezas ha permitido discernir tipos morfológicos. En otras palabras, "se basa en la identificación de atributos particulares, en la identificación de una regularidad y recurrencia en variantes morfológicas específicas, de índole técnica y/o funcional, o bien de características que particularizan un diseño, haciéndolo distinguible del conjunto instrumental" (Hocsman 2010:61). Unido a este análisis se encuentra la identificación del proceso de producción de las piezas, para los cuales se siguen las variables y los lineamientos metodológicos propuestos por Aschero (1975, 1983). Lo que se pretende aquí es poder reconocer las formas base de los artefactos formatizados a partir de la identificación de atributos específicos. En este punto discriminar entre formas base lascas y formas base bifaces se vuelve clave para inferir si se tratan de secuencias de reducción cortas o de aquéllas que implican un adelgazamiento de la pieza y la configuración de la arista. En este sentido, adoptamos la clasificación de Aschero y Hocsman (2004) referente a los subtipos morfológicos dentro del grupo bifaces, basándose en la extensión, profundidad de los lascados sobre las caras y la extensión del filo sobre la arista. El empleo de esta variedad de atributos permitirá la adscripción de los cabezales a tipos morfológicos conocidos. Los tipos morfológicos considerados son aquellos descriptos por diversos autores para las regiones que rodean a los valles mesotermales del Norte Argentino, siempre que provengan de contextos datados y cuya morfología haya sido claramente descrita (Tabla 1). Dado que los cabezales considerados remiten a un marco espacio-temporal específico, el uso de estas categorías nos permitirá proponer momentos en los cuales los cabezales líticos del valle de Santa María se encontraban en uso.

Mediante la descripción de las series técnicas (sensu Aschero 1975) indagaremos sobre la existencia de patrones en la formatización de filos o bordes de limbos o pedúnculos que destaquen una pieza sobre otras. Asimismo, utilizaremos la categoría de clase técnica definida por Aschero y Hocsman (2004), con el fin de evaluar el grado de inversión de trabajo en los cabezales.

Para poder llevar a cabo dicha descripción son cruciales las características macroscópicas de la materia prima que fue utilizada como soporte. En relación a esto último, contamos con el conocimiento de la base regional de recursos líticos del valle de Santa María, conformada por la localización de fuentes potenciales y efectivas de recursos líticos como vulcanitas y cuarzos (Carbonelli 2011), principales materias primas utilizadas para la confección de cabezales líticos.

Es necesario aclarar que adherimos a la postura de Ratto (2003) de utilizar el concepto de cabezales líticos, reservando la denominación de puntas de proyectil a aquellas piezas que forman parte de un sistema técnicoarrojadizo, con lafinalidad de penetrar la presa, luego de realizaruna trayectoria dentro de un fluido-aire. De esta manera, Ratto (2003) las diferencia de las puntas de mano, las cuales penetran las presas mediante un esfuerzo muscular y no realizan trayectoria alguna.

\section{Resultados}

En total se analizaron 200 cabezales líticos, los cuales pertenecen tanto a las colecciones de museos como a las recolecciones de superficie (Tabla 2). El 53\% de la muestra ( $\mathrm{N}=106$ ) se encuentra fracturado, encontrándose una mayor cantidad de especímenes en ese estado dentro de los cabezales líticos que provienen de las recolecciones de superficie $(\mathrm{N}=60$, un $80 \%$ ).

\begin{tabular}{|c|c|c|c|}
\hline Colección /Recolección & Enteras & Fragmentadas & $\mathrm{N}$ \\
\hline Terraza de Andalhuala & 7 & 9 & 16 \\
\hline Caspinchango & 4 & 2 & 6 \\
\hline Abra del Toro & 4 & 49 & 53 \\
\hline Colección Fundación Félix de Azara & 15 & 7 & 22 \\
\hline Colección Methfessel (Museo de Cs. Nts., La Plata) & 0 & 6 & 6 \\
\hline Colección Lafone Quevedo (La Plata) & 3 & 4 & 7 \\
\hline Colección Moreno 2 (La Plata) & 29 & 23 & 52 \\
\hline Colección Methfessel (Museo Etnográfico, UBA) & 32 & 6 & 38 \\
\hline Total & 94 & 106 & 200 \\
\hline
\end{tabular}


Tabla 3. Tipos morfológicos por materias primas.

Morphological types by raw materials. Parentheses indicate percentages.

\begin{tabular}{|c|c|c|c|c|c|c|c|c|c|c|}
\hline $\begin{array}{c}\text { Tipos } \\
\text { morfológicos }\end{array}$ & Obs. & And. & Bas. & $\mathrm{Cu}$ & Cua. & Síl. & Rio. & Indet. & $\begin{array}{l}\text { Provenientes } \\
\text { de recolección } \\
\text { sistemática }\end{array}$ & Total \\
\hline ICc4 & - & $4(100)$ & - & - & - & - & - & - & $\begin{array}{l}2 \\
(50)\end{array}$ & $\begin{array}{l}4 \\
(100)\end{array}$ \\
\hline PChB & - & $\begin{array}{l}2 \\
(40)\end{array}$ & $1(20)$ & $\begin{array}{l}2 \\
(40)\end{array}$ & & - & - & & 0 & $\begin{array}{l}5 \\
(100)\end{array}$ \\
\hline $\begin{array}{l}\text { Ayampitín, } \\
\text { PCzA }\end{array}$ & - & $\begin{array}{l}14 \\
(58,3)\end{array}$ & $2(8,3)$ & $\begin{array}{l}3 \\
(12,5)\end{array}$ & $\begin{array}{l}1 \\
(4,1)\end{array}$ & - & $\begin{array}{l}4 \\
(16,6)\end{array}$ & - & $\begin{array}{l}1 \\
(4,1)\end{array}$ & $\begin{array}{l}24 \\
(100)\end{array}$ \\
\hline PChE & $1(6,2)$ & $\begin{array}{l}6 \\
(37,5)\end{array}$ & $\begin{array}{l}7 \\
(43,7)\end{array}$ & $1(6,2)$ & - & - & - & $1(6,2)$ & $\begin{array}{l}2 \\
(12,5)\end{array}$ & $\begin{array}{l}16 \\
(100)\end{array}$ \\
\hline $\mathrm{PChF}$ & - & $\begin{array}{l}3 \\
(75)\end{array}$ & - & $\begin{array}{l}1 \\
(25)\end{array}$ & - & - & - & - & $\begin{array}{l}1 \\
(25)\end{array}$ & $\begin{array}{l}4 \\
(100)\end{array}$ \\
\hline PPB & - & - & $1(100)$ & - & - & - & - & - & $\begin{array}{l}1 \\
(100)\end{array}$ & $\begin{array}{l}1 \\
(100)\end{array}$ \\
\hline PPC & $4(19,1)$ & $\begin{array}{l}9 \\
(42,8)\end{array}$ & $\begin{array}{l}1 \\
(4,7)\end{array}$ & $\begin{array}{l}6 \\
(28,5)\end{array}$ & $\begin{array}{l}1 \\
(4,7)\end{array}$ & - & - & - & $\begin{array}{l}3 \\
(14,2)\end{array}$ & $\begin{array}{l}21 \\
(100)\end{array}$ \\
\hline QSB & $1(16,6)$ & $\begin{array}{l}1 \\
(16,6)\end{array}$ & $\begin{array}{l}1 \\
(16,6)\end{array}$ & $\begin{array}{l}1 \\
(16,6)\end{array}$ & - & $\begin{array}{l}2 \\
(33,3)\end{array}$ & - & - & 0 & $\begin{array}{l}6 \\
(100)\end{array}$ \\
\hline QSF & - & $\begin{array}{l}4 \\
(57,1)\end{array}$ & $\begin{array}{l}2 \\
(28,5)\end{array}$ & - & & - & $\begin{array}{l}1 \\
(14,2)\end{array}$ & & $\begin{array}{l}2 \\
(28,5)\end{array}$ & $\begin{array}{l}7 \\
(100)\end{array}$ \\
\hline Total & 6 & 43 & 15 & 14 & 2 & 2 & 5 & 1 & 12 & 88 \\
\hline
\end{tabular}

Del total de cabezales líticos analizados la mayoría $(\mathrm{N}=112)$ no pudieron ser identificadas. En esta categoría predominan los especímenes provenientes de nuestras recolecciones superficiales, tanto en la Mesada de Andalhuala Banda como en Abra del Toro. En ambos casos sobresalen las fragmentos limbo-apicales y limbo-basales de puntas de proyectil apedunculadas. Consideramos que podrían tratarse de preformas o puntas fracturadas de lanceoladas pequeñas $(\mathrm{PChE})$ o lanceoladas grandes (PCza o Ayampitín). A manera de hipótesis de trabajo, podemos atribuir la elevada frecuencia de ejemplares fracturados a que fueron encontrados en espacios utilizados para el descarte y reparación de los cabezales líticos.

Por otra parte, dentro del conjunto de la muestra, 88 piezas pudieron ser asignadas a tipos morfológicos (Tablas 1 y 3). Hemos reconocido en los cabezales líticos 10 tipos morfológicos que han sido definidos para la región de Antofagasta de la Sierra (Hocsman 2006, 2010; Martínez 2003) y que a su vez presentan cronologías y contextos conocidos (Tabla 1). La adscripción a los mismos se encuentra sustentada en el diseño de los cabezales, pero fundamentalmente en la congruencia con las dimensiones establecidas para los tipos morfológicos básicos (Tabla 4).

Al concentrar el análisis en las materias primas podemos destacar el predominio de los recursos locales (Tabla 3) (andesita, basalto, cuarzo, cuarcita) por sobre los alóctonos (obsidianas, riolitas y sílices) (Carbonelli
2012). Destacamos que dentro del primer grupo, las vulcanitas (andesitas y basaltos) concentran el 65,9\% de los tipos morfológicos, encontrándose el cuarzo en una proporción menor pero significativa dadas sus cualidades distintivas para la talla. Las vulcanitas se encuentran presentes a lo largo de la secuencia cronológica que acompaña a cada tipo, encontrándose representadas cada una en nueve de los 10 tipos morfológicos descriptos.

\section{Formatización de los tipos morfológicos}

En este acápite inferiremos el proceso de formatización de los tipos morfológicos reconocidos y las posibles causas de su abandono, al momento de ser registrados por nosotros o por investigadores anteriores, quienes fueron los que conformaron las colecciones que mencionamos con anterioridad. Las variables utilizadas son formas base (en el caso que se haya podido distinguir un atributo morfológico distintivo), clase técnica, serie técnica y fractura. Esta última variable nos permitiría reconocer, en caso de ser una fractura diagnóstica, un error de talla o una fractura de impacto, lo que hubiera terminado con la vida útil de la pieza.

En el caso del tipo morfológico ICc4 (Figura 3 (1) y (2)) de las cuatro piezas reconocidas, dos fueron formatizadas a partir de bifaces y dos a partir de lascas (Tabla 5). La alternancia entre estas dos formas base fue detallada tanto para el norte como el sur de la Puna 
Tabla 4. Dimensiones establecidas para los tipos morfológicos.

Extraído de Hocsman (2006), a excepción de Ayampitín (Gonzalez 1960) y PCzA (Martínez 2014).

Dimensions established for morphological types. Excerpted from Hocsman (2006), except Ayampitín (González 1960) and PCzA (Martínez 2014).

\begin{tabular}{|c|c|c|c|c|c|}
\hline Dimensiones & $\begin{array}{l}\text { ICc4 } \\
\text { (en mm) }\end{array}$ & $\begin{array}{l}\text { PChB } \\
\text { (en mm) }\end{array}$ & $\begin{array}{l}\text { PCzA } \\
\text { (en mm) }\end{array}$ & $\begin{array}{l}\text { Ayampitín } \\
\text { (en mm) }\end{array}$ & $\begin{array}{l}\text { PChE } \\
\text { (en mm) }\end{array}$ \\
\hline Largo Promedio & 26,30 DS: 4,48 & 43,35 DS: 9,40 & 100 (estimada) & & 30,27 DS: 3,56 \\
\hline Largo Máximo & & $50,00-36,70$ & $60-100$ & $45,00-100$ & $34,80-25,20$ \\
\hline Ancho promedio & 20,02 DS: 2,58 & 24,05 DS: 3,75 & 16,39 DS: 1,11 & & 15,80 DS: 1,63 \\
\hline Ancho máximo & & $26,70-21,40$ & $18,86-14,70$ & $24,00-16$ & $18,20-13,60$ \\
\hline $\begin{array}{l}\text { Espesor } \\
\text { promedio }\end{array}$ & 5,10 DS: 1,38 & 11,70 DS: 2,55 & 10,09 DS: 1,08 & & 6,53 DS: 1,03 \\
\hline Espeso máximo & & $13,50-9,90$ & $12,06-8,08$ & & $8,30-5,30$ \\
\hline Dimensiones & PChF & PPC & QSB & QSF & PPB \\
\hline Largo Promedio & & 41,80 DS: 2,62 & 41,19 DS: 9,91 & 60,06 DS: 6,24 & 33,87 DS: 2,70 \\
\hline Largo Máximo & 100 & $44,40-38,30$ & $63,30-30,20$ & $64,60-49,30$ & $38,60-30,50$ \\
\hline Ancho promedio & 26,13 DS: 2,41 & 18,52 DS: 1,50 & 26,96 DS: 4,24 & 32,93 DS: 1,88 & 22,27 DS: 3,60 \\
\hline Ancho máximo & $28,40-21,70$ & $20,90-17,10$ & $35,10-19,6$ & $36,20-30,40$ & $28,10-17,30$ \\
\hline $\begin{array}{l}\text { Espesor } \\
\text { promedio }\end{array}$ & 11,76 DS: 1,86 & 8,15 DS: 1,95 & 8,21 DS: 1,31 & 10,12 DS: 2,11 & 6,64 DS: 0,63 \\
\hline $\begin{array}{l}\text { Espesor } \\
\text { máximo }\end{array}$ & $14,50-9,20$ & $11,70-5,90$ & $11,50-5,30$ & $13,50-7,70$ & $7,50-5,80$ \\
\hline
\end{tabular}

(Hocsman et al. 2012). La forma base "biface" fue reconocida en particular a partir de la observación de atributos diagnósticos: filo normal con borde irregular y arista sinuosa irregular, filo perimetral y sección transversal biconvexa, con lascados profundos, extendidos o parcialmente extendidos. Consideramos que se trata de bifaces parciales, ya que observamos en ellos una formatización con lascados marginales parcialmente extendidos (Tabla 6). Esto se condice con la categoría de clase técnica: en los dos casos que la forma base fue un bifaz, fue utilizada la reducción bifacial, donde se trabajaron las caras de los ejemplares, buscando una geometría específica (Aschero y Hocsman 2004) sin llegar a reducir toda la pieza.

En cuanto a los ejemplares del tipo morfológico ICc4 confeccionados sobre formas base lasca, la formatización es aún menor. Registramos en dichas piezas un trabajo no invasivo bifacial, donde como describen Hocsman y Escola (2006-2007) el énfasis de los talladores se encontraba en la búsqueda de unos filos particulares, obtenidos mediante lascados que afectan primordialmente los bordes, y no las caras de los cabezales líticos. Prueba de ello es la serie técnica: se formatizaron estos dos ejemplares mediante lascados marginales de profundidad marginal o ultramarginal.

Precisamente, en referencia al proceso de producción de los artefactos líticos, uno de ellos presenta una fractura lateral (Tabla 7). La misma es reconocible por presentar una forma geométrica recta, de superficie normal y sección transversal plana. La misma se origina como consecuencia de "la aplicación de fuerza excesiva durante la percusión en piezas que están mal sostenidas" (Weitzel 2012:45).

En contraposición al tipo morfológico descrito anteriormente, los ejemplares que hemos clasificado como QSB (N=6) (Figura 4(3), (4), (5) y (6)) presentan una mayor inversión de trabajo. Esto se denota en la utilización del adelgazamiento bifacial en dos piezas y la reducción bifacial en tres piezas (Tabla 5). Ambas clases de técnicas se encuentran entre las tres primeras en esfuerzo de talla (Hocsman y Escola 2006-2007). Debido a que las piezas presentan sus superficies cubiertas por lascados posteriores solo nos fue posible reconocer la forma base en un caso, el cual presenta trabajo no invasivo bifacial, en este ejemplar, la forma base resultó ser una lasca.

Un rasgo distintivo para este tipo morfológico, definido por Martínez (2003, 2007), es que los bordes del pedúnculo evidencian retoque alterno. Lo hemos observado en los ejemplares mediante la técnica de retalla - retoque extendido profundo y retoque marginal. Debemos destacar que en cuanto a su longitud, los 
Tabla 5. Formas base y clase técnica por grupo morfológico. Base forms and technical class by morphological group.

\begin{tabular}{lllllll}
\hline & \multicolumn{3}{c}{ Formas base } & \multicolumn{3}{c}{ Clase técnica } \\
\hline $\begin{array}{l}\text { Tipo } \\
\text { morfológico }\end{array}$ & Bifaz & Lasca & $\begin{array}{l}\text { Adel. } \\
\text { Bif }\end{array}$ & $\begin{array}{l}\text { Adel. } \\
\text { Unif }\end{array}$ & $\begin{array}{l}\text { Red. } \\
\text { Bif. }\end{array}$ & $\begin{array}{l}\text { Trab. } \\
\text { No } \\
\text { inv. } \\
\text { Bif }\end{array}$ \\
\hline ICc4 & 2 & 2 & - & - & 2 & 2 \\
QSB & - & 1 & 2 & - & 3 & 1 \\
Ayampitín, & 1 & 3 & 9 & - & 15 & - \\
PCzA & & & & & & \\
QSF & - & 2 & 1 & 1 & 5 & - \\
PChF & - & - & - & - & 4 & - \\
PPB & - & - & - & - & 1 & - \\
PChB & - & 2 & 2 & 1 & 2 & - \\
PChE & 4 & 3 & 6 & - & 10 & - \\
PPC & 3 & 1 & 5 & - & 12 & 4 \\
\hline
\end{tabular}

ejemplares analizados por nosotros son más pequeños que el tipo básico (Martínez 2007). En este caso, entendemos que se debe se trata de "tipos morfológicos mantenidos" (Martínez 2007), es decir piezas que por mantenimiento o reactivación, vieron reducido su tamaño original.

En cuanto a sus fracturas (Tabla 7), hemos relevado dos curvadas, precisamente en los ejemplares que corresponden a este diseño. Se tratan de fracturas que atraviesan transversalmente las piezas, afectando en mayor medida al limbo. Como establece (Weitzel 2012) son de origen multicausal, sin un diagnóstico definido: errores de talla, por un golpe demasiado fuerte, por pisoteo, uso e impacto.

En otro orden, dentro de los tipos morfológicos reconocidos, hemos decidido analizar en forma conjunta especímenes identificados como "puntas Ayampitín" o como Peñas de la Cruz A (N=24) (Figura 4(7) a la (14)). Esta decisión obedece a la

Tabla 6. Serie técnica por tipo morfológico.

Technical series by morphological type.

\begin{tabular}{|c|c|c|c|c|c|c|c|c|c|}
\hline $\begin{array}{l}\text { Serie } \\
\text { técnica }\end{array}$ & ICc4 & QSB & $\begin{array}{l}\text { Ayampitín, } \\
\text { PCzA }\end{array}$ & QSF & $\mathrm{PChF}$ & PPB & PChB & PChE & PPC \\
\hline $\begin{array}{l}\text { Micro-retoque } \\
\text { parcialmente } \\
\text { extendido } \\
\text { marginal }\end{array}$ & 1 & - & - & - & - & - & - & - & - \\
\hline $\begin{array}{l}\text { Retoque marginal } \\
\text { ultramarginal }\end{array}$ & 1 & - & - & - & - & - & - & - & 1 \\
\hline $\begin{array}{l}\text { Retoque } \\
\text { parcialmente } \\
\text { extendido } \\
\text { marginal }\end{array}$ & 1 & - & 2 & 1 & 1 & - & - & 2 & - \\
\hline $\begin{array}{l}\text { Retoque } \\
\text { parcialmente } \\
\text { extendido } \\
\text { ultramarginal }\end{array}$ & 1 & - & - & - & - & - & - & - & - \\
\hline $\begin{array}{l}\text { Retalla extendido } \\
\text { profundo }\end{array}$ & - & 4 & 1 & - & 1 & - & - & - & - \\
\hline $\begin{array}{l}\text { Retoque marginal } \\
\text { marginal }\end{array}$ & - & 1 & 1 & - & - & - & - & - & - \\
\hline $\begin{array}{l}\text { Retoque extendido } \\
\text { profundo }\end{array}$ & - & 1 & 11 & 4 & 2 & - & 5 & 10 & 16 \\
\hline $\begin{array}{l}\text { Retoque } \\
\text { parcialmente } \\
\text { extendido } \\
\text { profundo }\end{array}$ & - & - & 3 & 1 & - & 1 & - & 4 & 1 \\
\hline $\begin{array}{l}\text { Retoque extendido } \\
\text { marginal }\end{array}$ & - & - & 3 & - & - & - & - & - & 3 \\
\hline $\begin{array}{l}\text { Retoque marginal } \\
\text { profundo }\end{array}$ & & - & 1 & - & - & - & - & - & - \\
\hline $\begin{array}{l}\text { Retalla } \\
\text { parcialmente } \\
\text { extendido } \\
\text { profundo }\end{array}$ & - & - & 2 & 1 & - & - & - & - & - \\
\hline Total & 4 & 6 & 24 & 7 & 4 & 1 & 5 & 16 & 21 \\
\hline
\end{tabular}




\begin{tabular}{|c|c|c|c|c|c|c|c|c|}
\hline $\begin{array}{c}\text { Tipos } \\
\text { morfológicos }\end{array}$ & Curvada & Lateral & $\begin{array}{l}\text { Burinación } \\
\text { de Impacto }\end{array}$ & $\begin{array}{l}\text { Por golpe } \\
\text { de buril }\end{array}$ & $\begin{array}{l}\text { Fractura } \\
\text { Moderna }\end{array}$ & $\begin{array}{l}\text { Acanaladura } \\
\text { por impacto }\end{array}$ & Perversa & Total \\
\hline ICc4 & 2 & 1 & - & - & - & - & - & 3 \\
\hline $\mathrm{PChB}$ & 1 & - & - & - & - & - & - & 1 \\
\hline $\begin{array}{l}\text { Ayampitín, } \\
\text { PCzA }\end{array}$ & 10 & - & 3 & 1 & - & - & 1 & 15 \\
\hline PChE & 1 & - & - & - & - & - & - & 1 \\
\hline $\mathrm{PChF}$ & 2 & - & - & - & 1 & - & - & 3 \\
\hline PPC & 2 & 1 & - & - & - & - & - & 3 \\
\hline QSB & 2 & - & - & - & - & - & - & 2 \\
\hline QSF & - & - & - & - & - & 1 & - & 1 \\
\hline Total & 20 & 2 & 3 & 1 & 1 & 1 & 1 & 29 \\
\hline
\end{tabular}

dificultad de discernir entre un tipo morfológico y otro cuando se solapan en sus dimensiones (Tabla 4) y fundamentalmente en su morfología. González (1960) define a las puntas Ayampitín como puntas lanceoladas o de forma de laurel o almendra, mientras que Martínez (2007) establece que el Tipo Morfológico PCzA se trataría de puntas apedunculadas de limbo lanceolado con bordes normales o dentados. Otro elemento en común entre ambos especímenes es la base convexa. No obstante, consideramos que la categoría definida por González (1960) contiene una variabilidad mayor a la referida. Por lo tanto, preferimos utilizar el criterio métrico de Martínez (2007), el cual otorga una mayor precisión cronológica y tipológica a la definición de los cabezales.

A la dificultad de diferenciar los diseños se suma la gran cantidad de piezas fragmentadas (15 sobre 24$)$, lo cual imposibilita establecer cuál fue el diseño final. Esta es la causa de sólo poder reconocer las formas base en cuatro piezas dentro de estos dos tipos morfológicos. Hemos identificado que tres ejemplares fueron formatizados a partir de lascas, reconocibles a partir de la presencia de atributos diagnósticos como talones y bulbos. El otro ejemplar fue formatizado a partir de un bifaz.

Dentro de la serie técnica predomina el retoque extendido profundo, seguidoporel retoque parcialmente extendido profundo y el retoque extendido marginal. La gran mayoría de estos cabezales líticos presentan sus caras retocadas o trabajadas en su totalidad (Tabla 6). De todo el conjunto instrumental éstos son los cabezales líticos con las frecuencias más elevadas de adelgazamiento bifacial y reducción bifacial (Tabla 5). Esto condice con las palabras de González (1960), quien estableció que se encontraban trabajadas en ambas caras por retoque a presión.

En relación a las fracturas, un dato relevante es que tres puntas presentan fracturas por burinación de impacto, la cual como su nombre lo indica, son causadas por el impacto con una sustancia dura o por la fuerza misma de la penetración (Weitzel 2012; Weitzel y Colombo 2006). En este mismo sentido, reconocimos en un ejemplar una acanaladura por impacto (Weitzel 2012). Tanto la fractura por burinación como de acanaladura por impacto son indicios que evidencian que dichos artefactos tuvieron una vida útil como cabezales líticos (Weitzel y Colombo 2006).

En otro orden, debemos destacar que otro ejemplar presenta una fractura perversa, común entre los bifaces o instrumentos que utilizan bifaces como formas base (Weitzel 2012).

Al detenernos en las piezas que hemos identificado con el tipo morfológico QSF $(\mathrm{N}=7)$, podemos mencionar que presentan una inversión de trabajo similar a los anteriores grupos descriptos: cinco piezas presentan reducción bifacial, una adelgazamiento bifacial y la restante adelgazamiento unifacial (Figura 4(15) a la (19)). En este último caso, el trabajo del tallador se centró en una de las dos caras, reduciendo su espesor y buscando una sección específica (Hocsman y Escola 2006-2007). Ya sea en una cara o en las dos, se formatizaron extensamente las superficies, prueba de ello es que hemos constatado el uso del retoque extendido y parcialmente extendido profundo, y el retoque parcialmente extendido marginal.

Existen, a su vez, otras consideraciones que podemos efectuar a partir de este tipo morfológico. En primera instancia, lo hemos definido como "una punta de proyectil con pedúnculo esbozado y hombros". Al respecto, debemos mencionar que ya Aschero et al. (1993-1994) señalaron que dicho diseño obedece en realidad a un proceso de reactivación por mantenimiento, siendo la forma original (o diseño básico) de tipo lanceolado o con un pedúnculo de base redondeada. Babot et al. (2013) señalan que también conforman indicios de reactivación la presencia de lascados irregulares, la 


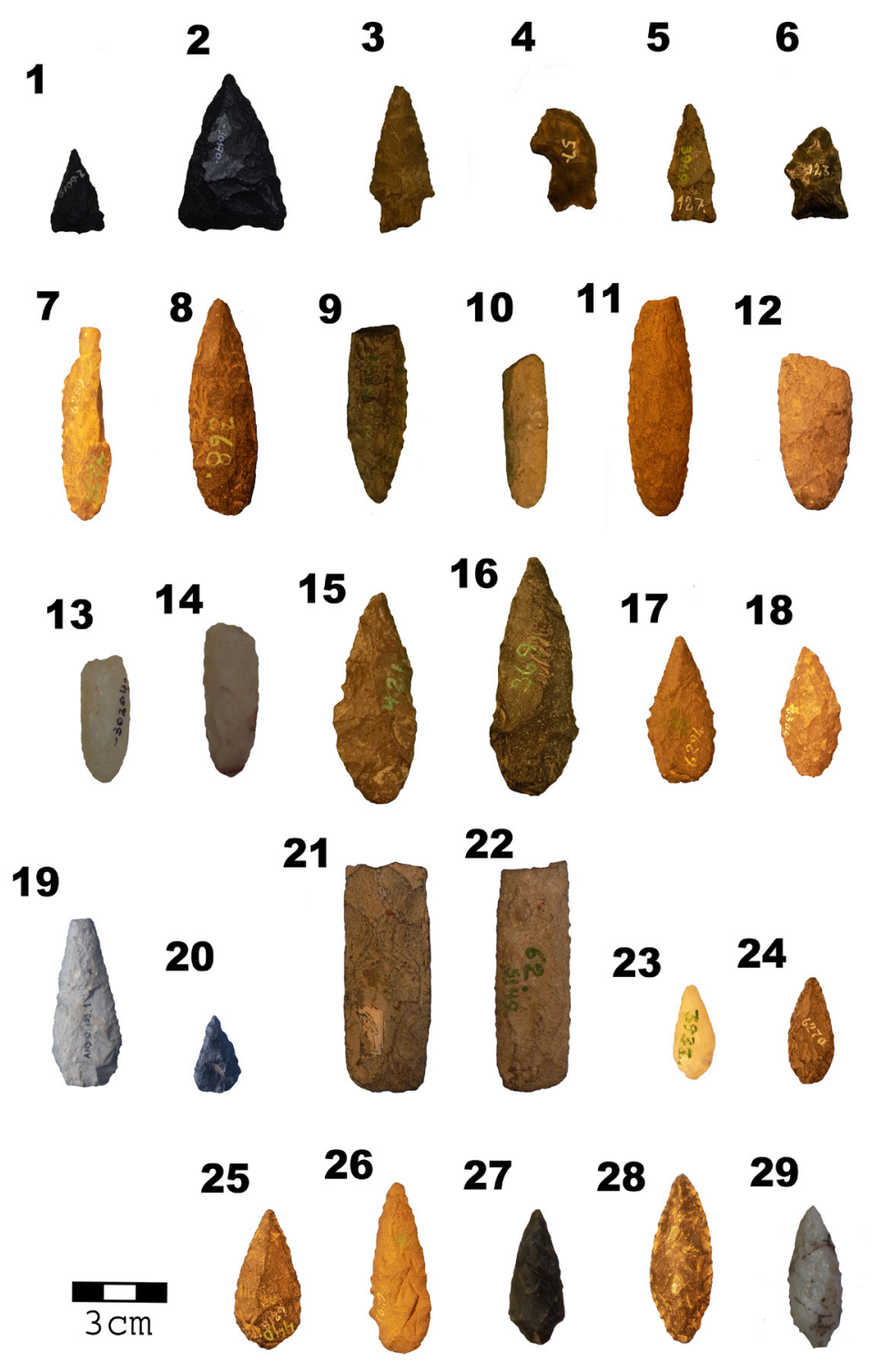

Figura 4. Tipos morfológicos identificados en las colecciones de museos y en las recolecciones superficiales. (1) y (2): ICc4; (3) a (6): QSB; (7) a (14): PCza; (15) a (19): QSF; (20): PPb; (21) y (22): PChF; (23) a (24): PChE; (25) y (26): PChB; (27) a (29): PPC. Número de piezas=1: MEJBA: 30179- Z-6019- ACD-C89; 2: MEJBA 30140- Z-1424- ACD-C89; 3: MLP-Ar-(blanco)130; 4: MLP-Ar-(blanco) 57; 5: MLP-Ar(blanco) 127; 6: MLP-Ar-(blanco) 123; 7: MLP-Ar-(blanco) 6259; 8: MLP-Ar-(verde) 368; 9: MLP-Ar-(blanco) 154; 10: MLP-Ar-(blanco) 553; 11: MLP-Ar-(verde) 372; 12: MLP-Ar-(verde) 394; 13: MEJBA: 30204- 6290-6355; 14: MEJBA: 30204- 6290-6355; 15: MLP-Ar-(verde) 421; 16: MLP-Ar-(verde) 369; 17: MLP-Ar-(blanco) 6294; 19: MLP-Ar-(blanco) 6304; 20: Recolección mesada de Andalhuala-Banda; 21: MLPAr-(negro) 574; 22: MLP-Ar-(verde) 62.5149; 23: MLP-Ar-(blanco) 6270; 24: MLP-Ar-(verde) 3932; 25: MLP-Ar-(verde) 440; 26: MLP-Ar(blanco) 6291; 27: MEJBA: 19580- ADA-C139; 28: MLP-Ar-(verde) 354; 29: MEJBA: 38014- 36-724- 5ch-272.

Morphological types identified in museum and surface collection. (1) and (2): ICc4; (3) to (6): QSB; (7) to (14): PCza; (15) to (19): QSF; (20): PPb; (21) y (22): PChF; (23) a (24): PChE; (25) and (26): PChB; (27) to (29): PPC. Número de piezas = 1: MEJBA: 30179- Z-6019-ACD-C89; 2: MEJBA 30140-Z-1424-ACD-C89; 3: MLP-Ar-(white) 130; 4: MLP-Ar-(white) 57; 5: MLP-Ar-(white) 127; 6: MLP-Ar-(white) 123; 7: MLPAr-(white) 6259; 8: MLP-Ar-(green) 368; 9: MLP-Ar-(white) 154; 10: MLP-Ar-(white) 553; 11: MLP-Ar-(green) 372; 12: MLP-Ar-(green) 394; 13: MEJBA: 30204- 6290-6355; 14: MEJBA: 30204- 6290-6355; 15: MLP-Ar-(green) 421; 16: MLP-Ar-(green) 369; 17: MLP-Ar-(white) 6294; 19: MLP-Ar-(white) 6304; 20: Collection mesada de Andalhuala-Banda; 21: MLP-Ar-(black) 574; 22: MLP-Ar-(green) 62.5149; 23: MLP-Ar-(white) 6270; 24: MLP-Ar-(green) 3932; 25: MLP-Ar-(green) 440; 26: MLP-Ar-(white) 6291; 27: MEJBA: 19580-ADA-C139; 28: MLP-Ar-(green) 354; 29: MEJBA: 38014- 36-724- 5ch-272. 
asimetría en la vista frontal, los bordes irregulares, un acortamiento en el largo del limbo y un marcado punto de inflexión entre el mismo y el pedúnculo. Todos estos atributos fueron observados en las piezas que componen nuestro conjunto de análisis.

Un dato particular, que no se repite en otro tipo morfológico, es que uno de los cabezales líticos tiene un filo en cuchillo. En este sentido, Aschero et al. (19941993:199) habían marcado que posiblemente estos artefactos tuvieran: "una función diferente a la de puntas de proyectil, funcionando como cuchillos o puntas de armas arrojadizas de corto alcance". Babot et al. (2013), mediante diferentes líneas de análisis, retomaron dicha temática y establecieron que las piezas del conjunto artefactual analizado por ellos fueron utilizadas, en primer lugar, como cabezales líticos, y luego, como cuchillos enmangados, tanto para procesar materiales animales como vegetales.

Deteniéndonos en el tipo morfológico $\mathrm{PChF}(\mathrm{N}=4)$ (Figura 4(21) y (22)), no pudimos identificar en dichos cabezales líticos las formas base. Esto se debió a que tres de los ejemplares se encontraban fracturados y el restante se manufacturó sobre cuarzo, una materia prima difícil para observar la formatización y los atributos de las formas base.

Los cuatro ejemplares fueron confeccionados mediante reducción bifacial, observándose retoque / retalla extendida profunda. Como en el resto de los artefactos formatizados descriptos, consideramos que, mediante dicha clase técnica, se trató de imponer una cierta forma geométrica, simétrica o no, a los artefactos (Hocsman y Escola 2006-2007). En referencia a las fracturas, en dos piezas hemos reconocido las de tipo "curvadas", donde no es factible identificar su origen, y una fractura "moderna" (Tabla 7). Nominalizamos de esta manera a esta fractura, dado que el color de la misma contrasta con el resto de la pieza, originada con seguridad por el pisoteo.

En cuanto al tipo morfológico PPB (Figura 4(20)), identificamos una sola pieza de basalto, la cual se encuentra entera. Este cabezal lítico fue recolectado en la Mesada de Andalhuala Banda, y no fue posible reconocer su forma base, el mismo presenta reducción bifacial. La adscripción a dicho tipo morfológico se encuentra dada no sólo por su morfología, sino principalmente por exhibir un limbo dentado (Hocsman 2006:259). En este caso, la forma del borde se obtuvo a través de retoques parcialmente extendidos profundos, de forma escamosa irregular, producto de una intensa reactivación (Tabla 6). Precisamente, el retoque escamoso es el que impide apreciar las aletas, a la cual hemos definido en espolón.

Dentro de la muestra que analizamos, el tipo morfológico $\mathrm{PChB}$ se encuentra integrado por cinco cabezales líticos, dos de ellos con formas base lasca (Tabla 5) (Figura 4 (25) y (26)). A excepción de una pieza de la que sólo tenemos un fragmento limbo basal, el resto presenta pedúnculo esbozado, lo cual para Hocsman (2006) es indicio de transformación de las mismas. En los cabezales líticos que analizamos existe uniformidad en la serie técnica: todos exhiben en sus caras retoques extendidos profundos (Tablas 5 y 6). Las mismas presentan en dos ejemplares adelgazamiento bifacial, en otros dos, reducción bifacial y un caso de adelgazamiento unifacial. Por otra parte, todas las puntas se encuentran enteras a excepción de una que presenta una fractura curvada, no diagnóstica.

El tipo morfológico PChE (N=16) (Figura 4(23) y (24)) es, dentro de nuestra muestra, uno de los de mayor frecuencia y de mayor diversidad en la representación de las materias primas, ya que fue formatizado en obsidiana, cuarzo, andesita, basalto y un recurso lítico indeterminado (Tabla 2). Al reparar en la clase técnica (Tabla 5) podemos deducir que todas las piezas con adelgazamiento bifacial $(\mathrm{N}=6)$ provienen de formas base bifaces y las que presentan reducción bifacial fueron formatizadas a partir de lascas. Una vía de análisis que colabora para afirmar que las piezas con adelgazamiento bifacial tuvieron como formas base biface es la serie técnica (Tabla 6): predomina el retoque parcialmente extendido profundo $(\mathrm{N}=10)$ y extendido profundo $(\mathrm{N}=4)$, atributos característicos de los bifaces stricto sensu (Hocsman 2006).

Dentro de este tipo morfológico encontramos dos variantes: una con pedúnculo esbozado y hombros $(\mathrm{N}=6)$ y otra apedunculada $(\mathrm{N}=9)$. Con respecto a esta última variante, los ejemplares se ajustan a lo que Aschero et al. (2011) han definido como diseños en "mandorla". Dicho diseño exhibe una forma geométrica con la apariencia de una almendra, donde el ancho máximo de la pieza se sitúa precisamente en el centro de la misma (Aschero et al. 2011)2. El ejemplar que resta corresponde a una pieza lanceolada que sobresale por su tamaño (largo 52 $\mathrm{mm}$, ancho $21 \mathrm{~mm}$ ) y que presenta similitudes con el tipo morfológico Af-D, definido para la Quebrada de Antofalla (Moreno 2010). Dicho tipo morfológico, que fue asignado funcionalmente tanto para el sistema de arco o lanzadera, se diferencia de nuestro espécimen por exhibir lascados unifaciales. Debemos destacar que en este tipo morfológico no hemos detectado una fractura diagnóstica, que nos permitiera reconocer errores de talla o fracturas por impacto (Tabla 6).

Finalmente, describiremos el tipo morfológico PPC (Figuras 4(27) a la (29)), que es probablemente el diseño más cercano a los contextos agro-pastoriles (Hocsman 2010). Es el tipo morfológico de mayor frecuencia en nuestra muestra $(\mathrm{N}=21)$. Fue confeccionado a partir de dos formas base, bifaces y lascas (Tabla 5). Como lo notamos al momento de describir el tipo morfológico PChE, la división entre dos formas bases distintas pudo dar lugar a dos tipos de inversión de trabajo bien diferenciadas: el adelgazamiento bifacial, un proceso 
técnico que involucraba utilizar formas-base secundarias (sensu Nami 1988) a bifaces en sentido estricto y bifaces parciales (Hocsman 2010) y la reducción bifacial, la cual probablemente se aplicó sobre lascas. Dentro de la formatización efectuada en las dos caras de cada artefacto, predomina el retoque extendido profundo, seguido por el retoque extendido marginal (Tabla 7).

Tres de los cabezales líticos asignados a este diseño se encuentran fracturados. Solo en uno de ellos pudimos identificar una fractura lateral (Tabla 7). La misma presenta una sección transversal plana, llevándose parte del limbo y el hombro (Weitzel 2012), generada por la aplicación de fuerza en el centro de la pieza, la que removió parte del borde originando una concavidad y un lascado más profundo que el resto (Weitzel y Colombo 2012). La misma sería el fruto de un error de talla.

\section{Discusión y Palabras Finales}

En este trabajo buscamos contribuir al conocimiento sobre las ocupaciones cazadoras-recolectoras en el valle de Santa María. Los resultados del análisis indican la existencia de coincidencias entre los diseños de cabezales líticos identificados en nuestra región de estudio y los registrados en la zona de puna argentina y chilena. Apoyándonos en esto, en este trabajo proponemos considerar estos diseños como indicadores de la profundidad temporal de las poblaciones de cazadoresrecolectores del valle, existentes desde el Holoceno Temprano. En consonancia con esto, entendemos que este trabajo es un aporte a las investigaciones desarrolladas por colegas en la región (Martínez et al. 2013; Somonte y Baied 2013).Un aspecto remarcable del presente estudio es la utilidad del análisis de colecciones, aún de las que carecen de datos precisos sobre su contexto de hallazgo, dado que pueden brindar informaciones en diversas escalas de análisis.

Antes de remitirnos a discutir sobre los alcances de nuestros resultados sobre las piezas que corresponden a tipos morfológicos, debe remarcarse que una importante cantidad de cabezales líticos que no pudieron ser asignados a tipos morfológicos son fragmentos que presentan marcadas similitudes con los diseños PChE y PCzA o Ayampitín, lo cual aumentaría la representación de dichos diseños en el valle.

En cuanto a las piezas de la colección Methfessell del Museo Etnográfico, se tratan de ejemplares cuya morfología es dudosa, mientras que los que pertenecen a la Fundación Félix de Azara serían preformas, cuyo diseño no se encuentra terminado. Coinciden en su morfología con los fragmentos apedunculados de la Mesada de Andalhuala Banda y Abra del Toro. Finalmente, las piezas que no fueron designadas a ningún tipo morfológico y que provienen de las colecciones Moreno, Lafone Quevedo y Methfessell del Museo de Ciencias Naturales, se encuentra fracturadas aunque factiblemente también se trate de lanceoladas pequeñas o grandes.

Debemos remarcar que, en todos los casos de cabezales líticos enteros o cuyas fracturas no impidieron reconocer su morfología, los diseños identificados son compartidos con otras regiones de los Andes Meridionales. En otras palabras, no hemos hallado diseños que tengan una distribución espacial acotada al valle de Santa María. No obstante, no descartamos la posibilidad de la existencia de diseños de carácter local.

En otro orden, la elevada frecuencia de cabezales líticos contribuye a sostener la existencia de una considerable intensidad de ocupaciones de cazadores-recolectores en el valle. Esto conforma un dato relevante, dada la importante dinámica del paisaje, lo cual sumado a las reiteradas ocupaciones posteriores (períodos Formativo, Tardío e Inka) invisibilizaron y obliteraron el registro perteneciente a grupos previos.

La presencia de diseños compartidos con otras regiones apoyaría la probable existencia de redes de circulación de información que vinculaban amplios espacios durante el Holoceno. Remarcamos que si bien existen variaciones en las morfologías, existe un solapamiento en las características métricas (tamaño) y en las proporciones de cada una de sus partes (pedúnculos, limbos, aletas, ápices). Esto se aplica especialmente con respecto a la región de Antofagasta del Sierra, con la cual se comparten diseños que otros autores (Hocsman 2006) consideraron de producción y distribución estrictamente local (tipo morfológico QSB).

Las materias primas presentes en la muestra se caracterizan por una marcada selección de las disponibles localmente en el valle. Esto se observa tanto en los ejemplares que provienen de las recolecciones superficiales como los de las colecciones de museos. Este patrón indica la manufactura local de la mayor parte de las piezas, a pesar de que los diseños sean compartidos con regiones distantes. En este marco proponemos que existirían rangos de movilidad acotados para las poblaciones del valle, lo cual no excluye un intenso flujo de individuos e información entre las dos ecorregiones, Puna y Montes de sierras y bolsones (Morello et al. 2012).

La tendencia sobre el consumo de recursos líticos cambia hacia los momentos de transición agropastoril, cuando se incorpora en mayor frecuencia la obsidiana para las puntas de proyectil. Un ejemplo consiste en el tipo morfológico denominado PPC. La incorporación de recursos alóctonos coincide con lo descripto por otros autores (Hocsman 2010; Yacobaccio et al. 2004) los cuales lo vinculan con un aumento en la amplitud e intensidad de los contactos entre regiones.

En el marco del análisis de los procesos de producción debe remarcarse el predominio de las clases técnicas de adelgazamiento y reducción bifacial. Esto último se corresponde con la gran cantidad de formas base bifaces encontradas entre las puntas lanceoladas, de grandes y pequeñas dimensiones. Con respecto a esto, 
a nivel analítico y de reconstrucción de la secuencia de producción, consideramos que en estos casos se trataron de bifaces modificados (Hocsman 2009). Es decir, bifaces cuya arista sinuosa fue modificada a arista regular para ser utilizado como soporte de instrumentos (Hocsman 2007). El uso de las clases técnica de adelgazamiento y reducción bifacial señalan un fuerte contraste con la tecnología de momentos agropastoriles (Carbonelli 2011; Hocsman 2006; Hocsman y Escola 2006-2007), marcada por una menor inversión en la formatización de instrumentos y formas base. $\mathrm{El}$ abundante uso de bifaces como formas base durante el Holoceno Temprano y Medio se ve apoyado por el análisis de los conjuntos pertenecientes a canteras, los cuales presentan una elevada frecuencia de bifaces (Carbonelli 2013). Sin embargo, debe remarcarse que a lo largo de toda la secuencia propuesta conviven dos modalidades de producción, una a partir de formas base bifaces y otra a partir de formas base lascas. Ambas fueron encontradas en cabezales líticos tanto de cronologías tempranas como de momentos del Holoceno Medio y en la transición con el período Formativo. Dado que nuestra muestra es pequeña no es factible construir un tendencia temporal en el empleo de formas base, si bien parece haber un aumento en el uso de bifaces a lo largo de la secuencia.

La gran diversidad de tipos morfológicos reconocidos en la muestra es un dato que consideramos pertinente señalar. Como describimos anteriormente, la variabilidad de diseños ha sido considerada en regiones vecinas como un factible indicador de la utilización de una diversidad de estrategias de caza, asociados a distintos tipos de sistemas de armas (Martínez y Aschero 2001; Ratto 2003). Precisamente, con respecto al uso, el análisis de las fracturas indica que parte de los cabezales líticos presentan evidencias vinculadas a su utilización como puntas de armas. Nos referimos concretamente a los casos que presentan burinación y acanaladura por impacto (Tabla 7).
A manera de agenda se abren una serie de interrogantes paracontinuar lainvestigación. Con respectoalosejemplares que provienen de nuestras recolecciones superficiales, nuestros trabajos futuros consistirán en efectuar sondeos con el objeto de obtener contextos estratificados, que puedan brindar cronologías absolutas. Esto se aplica especialmente al caso del Taller Abra del Toro, donde encontramos una importante concentración de puntas de proyectil. En relación a esto, nos proponemos también profundizar en las características de distribución de las puntas de proyectil en el valle. En otras palabras, comparar espacios con una alta concentración de cabezales versus aquellos con escasa representación.

A nivel analítico, continuaremos indagando sobre dos interrogantes de los cuales hemos efectuado un primer acercamiento en este trabajo. En primer lugar, el de la movilidad de estos grupos y su rango de acción. Y en segundo término, el rol que ocupó el trabajo bifacial en las estrategias tecnológicas.

Agradecimientos: Este trabajo se realizó en el marco de la beca posdoctoral de CONICET de Juan Pablo Carbonelli y la beca doctoral de CONICET de Agustín Agnolin y con el financiamiento de ANPCYT PICT2010-2013 (2011-2014). Agradecemos especialmente a la Fundación Félix de Azara y al encargado del museo Sergio Bogan; al Museo de Ciencias Naturales de La Plata y a las encargadas del Depósito 25, la Dra. Ana Igareta y a la Lic. Jorgelina Collazo y a los encargados del Depósito de Arqueología del Museo Etnográfico, Juan Manuel Estévez, Alejandra Reynoso, Marina Marchegiani y Gabriela Amiriatti. Agradecemos también a Alejandro Haber por permitirnos reproducir su mapa. Por último nuestro agradecimiento va dirigido a los evaluadores que han mejorado sustancialmente este manuscrito a partir de sus comentarios y sugerencias.

\section{Referencias Citadas}

Álvarez Larraín, A. 2010. Arquitectura y paisajes en la localidad arqueológica de Andalhuala (valle de Yocavil, Catamarca). Revista del Museo de Antropología 3:33-48.

Álvarez Larraín, A. y S. Lanzelotti 2013. Habitar y cultivar en el este del Valle de Yocavil. En La Espacialidad en Arqueología. Enfoques, Métodos y Aplicación, editado por I. Gordillo y J.M. Vaquer, pp.151-191. Editorial Abya Yala, Quito.

Aschero, C. 1975. Ensayo para una clasificación morfológica de artefactos líticos aplicados a estudios tipológicos comparativos. Informe a CONICET, Buenos Aires.

Aschero, C. 1983. Revisiones ensayo para una clasificación morfológica de artefactos líticos. Apéndices A y B. Cátedra de Ergología y Tecnología, UBA, Buenos Aires.

Aschero, C. 1984. El sitio ICC-4: Un asentamiento precerámico en la Quebrada de Inca Cueva (Jujuy, Argentina). Estudios Atacameños 7:62-72.

Aschero, C. 1994. Reflexiones desde el Arcaico Tardío (60003000 AP). Rumitacana 1:13-17.
Aschero, C.A., D. Elkin y E. Pintar 1991. Aprovechamiento de recursos faunísticos y producción lítica en el Precerámico Tardío. Un caso de estudio: Quebrada Seca 3 (Puna Meridional Argentina). Actas del XI Congreso Nacional de Arqueología Chilena 2:101-114. Santiago.

Aschero, C y S. Hocsman 2004. Revisando cuestiones tipológicas en torno a la clasificación de artefactos bifaciales. En Temas de Arqueología, Análisis Lítico, editado por A. Acosta, D. Loponte y M. Ramos, pp. 7-25. Universidad Nacional de Luján, Luján.

Aschero, C., S. Hocsman y N. Ratto 2011. Las puntas de proyectil en "mandorla" de Inca Cueva 7: caracterización tipológica e historia de vida (Puna de Jujuy, Argentina). Estudios Atacameños 41:5-28.

Aschero, C., L.M. Manzi y A.G. Gómez 1993-1994. Producción lítica y uso del espacio en el nivel 2b4 de Quebrada Seca 3. Relaciones de la Sociedad Argentina de Antropología XIX:191214.

Babot, M.P., S. Hocsman y G.R. Cattáneo 2013. Assesing the life 
history of projectile points/knives from the Middle Holocene of Argentina's Southern Puna. Quaternary International 287:3-19.

Bossi, G.E., S.M. Georgieff, I. Gavrilof, L.M. Ibañez y C.M. Muruaga 2001. Cenozoic evolution of the intramontane Santa María basin, Pampean Ranges, norhwestern Argentina. Journal of South American Earth Sciences 14:725-734.

Carbonelli,J.P. 2011. Base regional de recursos líticos y fuentes de materias primas al sur del Valle de Yocavil. Estudios Sociales del NOA 12:111-137.

Carbonelli, J.P. 2013. Técnicas Líticas en Paisajes Cazadores y Agropastoriles al sur del Valle de Yocavil. Tesis Doctoral. Facultad de Filosofía y Letras, Universidad de Buenos Aires, Buenos Aires.

Chiappe, D. 1967. Hallazgos precerámicos efectuados en Chiquimil (actual Entre Ríos) del Valle de Santa María, Provincia de Catamarca. Anales de Arqueología y Etnología 22:101-107.

Cigliano, E. 1961. Noticia sobre una nueva industria precerámica en el Valle de Santa María (Catamarca): El Ampajanguense. Anales de Arqueología y Etnología 16:169-179.

Cigliano, E., S. Bereterbide, B. Carnevali, A.M. Lorandi y M.N. Tarragó 1962. El Ampajanguense. Publicación del Instituto de Antropología 5:7-104.

Cortés, L.A. 2013. A través del paisaje, a través de los cuerpos. Contextos funerarios del sur del valle del Cajón (Noroeste argentino, 6000 - 1300 años AP). Relaciones de la Sociedad Argentina de Antropología XXXVIII:293-319.

Durando, P., M. García Salemi y G. Platanía 1986. Estudios geomorfológicos; paleoclimas, dataciones relativas y tipología a partir de paleolitos del Valle de Santa María (Provincias de Catamarca y Tucumán, República Argentina). En Actas y Trabajos del VI Congreso Peruano: Hombre y Cultura Andina, editado por F. Iriarte Brenner, pp. 89-109. Universidad Garcilaso de la Vega, Lima.

Gómez Augier, J. y M. Caria 2012. Los paleoambientes y los procesos culturales en el noroeste argentino: una aproximación desde la arqueología de Tucumán. Acta Geológica 24 (1-2):8097.

González, A.R. 1952. Antiguo horizonte precerámico en las Sierras Centrales de Argentina. Runa 5:110-113.

González, A.R. 1960. La estratigrafía de la gruta de Intihuasi (prov. de San Luis, R. A.) y sus relaciones con otros sitios precerámicos de Sudamérica. Revista del Instituto de Antropología I:5-296

Haber, A. 1999. Una Arqueología de los Oasis Puneños. Domesticidad, Interacción e Identidad en Antofalla, I y II Milenios d.C. Tesis doctoral. Facultad de Filosofía y Letras, Universidad de Buenos Aires, Buenos Aires.

Hocsman, S. 2006. Producción Lítica, Variabilidad y Cambio en Antofagasta de la Sierra -ca. 5500-1500 AP. Tesis Doctoral. Facultad de Ciencias Naturales y Museo, Universidad Nacional de La Plata, La Plata.

Hocsman, S. 2007. Producción de bifaces y aprendices en el sitio Quebrada Seca 3 -Antofagasta de la Sierra, Catamarca- (55004500 años AP). En Producción y Circulación Prehispánica de Bienes en el Sur Andino, compilado por A. Nielsen, M.C. Rivolta, V. Seldes, M. M. Vázquez y P. Mercolli, pp. 55-83. Editorial Brujas, Córdoba.

Hocsman, S. 2009. Variabilidad de casos de reciclaje en artefactos formatizados tallados: Peñas Chicas 1.1 (Antofagasta de la Sierra, Catamarca) como caso de estudio. Relaciones de la Sociedad Argentina de Antropología XXXIV:351-358.
Hocsman, S. 2010. Cambios en las puntas de proyectil durante la transición de cazadores-recolectores a sociedades agro-pastoriles en Antofagasta de la Sierra (Puna Argentina). Arqueología 16:59-86.

Hocsman, S. y P. Escola 2006-2007. Inversión de trabajo y diseño en contextos líticos agro-pastoriles (Antofagasta de la Sierra, Catamarca). Cuadernos del Instituto Nacional de Antropología y Pensamiento Latinoamericano 21:75-90.

Hocsman, S., J. Martínez, C.A. Aschero y A. Calisaya 2012. Variability of Triangular Non-Stemmed Projectile points of Early Hunter-Gatherers of the Argentinian Puna. En Southbound. Late Pleistocene Peopling of Latin America, editado por L. Miotti, M. Salemme, N. Flegenheimer y T. Goebel, pp. 63-69. Current Research in The Pleistonce, Texas University.

Hocsman, S., C. Somonte, M.P. Babot, A.R. Martel y A. Toselli 2003. Análisis de los materiales líticos de un sitio a cielo abierto del área valliserrana del NOA: Campo Blanco, Tucumán. Cuadernos de la Facultad de Humanidades y Ciencias Sociales 20:325-350.

Lanzelotti, S. 2012. Uso del Espacio y Construcción del Paisaje Agrícola en la Cuenca del río Caspinchango, Valle de Yocavil, Catamarca. Tesis Doctoral. Facultad de Filosofía y Letras, Universidad de Buenos Aires, Buenos Aires.

Lavallée, D. 2000. The First South Americans. The Peopling of a Continent from the Earliest Evidence to High Culture. The University of Utah Press, Salt Lake City.

López, G.E.J. y F. Restifo 2017. El sitio Alero Cuevas Puna de Salta Argentina: secuencias de cambios en artefactos líticos y resolución cronológica macrorregional durante el Holoceno Temprano y Medio. Chungara Revista de Antropología Chilena 49:49-63.

Márquez Miranda, F. y E. Cigliano 1961. Un nuevo "antigal" catamarqueño: el yacimiento arqueológico de Rincón Chico (Dpto. de Santa María, Prov. de Catamarca). Revista del Museo de La Plata 5 (27):179-192.

Martínez, J. 2003. Ocupaciones Tempranas y Tecnología de Caza en la Microrregión de Antofagasta de la Sierra (100007000 AP). Tesis Doctoral. Facultad de Ciencias Naturales e Instituto Miguel Lillo, Universidad Nacional de Tucumán, Tucumán.

Martínez, J. 2007. Ocupaciones humanas tempranas y tecnología de caza en Antofagasta de la Sierra, Puna Meridional Argentina (10000-7000). Revista Cazadores Recolectores del Cono Sur 2:129-151.

Martínez, J. 2014. Rastreando cazadores en la puna: proyectiles en movimiento y su registro. En Artefactos Líticos, Movilidad, Funcionalidad de Sitios: Problemas y Perspectivas, editado por P. Escola y S. Hocsman, pp. 11-22. BAR, Oxford.

Martínez, J., E. Mauri, C. Mercuri, M. Caria y N. Oliszewski 2011. Ocupaciones humanas tempranas en el centro-oeste de Tucumán... ¿hay una vida más allá del Formativo? En Poblaciones Humanas y Ambientes en el Noroeste Argentino durante el Holoceno Medio, editado por M. Mondini, J. Martínez, H. Muscio y M.B. Marconetto, pp.119-121. Taller de Arqueología, Córdoba.

Martínez, J., E. Mauri, C. Mercuri, M. Caria y N. Oliszewski 2013. Mid-Holocene human occupations in Tucumán (northwest Argentina). Quaternary International 307: 87-95.

Morello, J., S. Mateucci, A. Rodríguez y M.E. Silva 2012. Ecorregiones y Complejos Ecosistémicos Argentinos. Primera edición, Orientación Grafica Editora, Buenos Aires. 
Moreno, E. 2010. Arqueología de la Caza de Vicuñas en el Área del Salar de Antofalla, Puna de Atacama. Una Aproximación desde la Arqueología del Paisaje. Tesis Doctoral, Facultad de Ciencias Naturales y Museo, Universidad Nacional de La Plata, La Plata.

Nami, H. 1988. Arqueología experimental, tecnología, artefactos bifaciales y modelos. Estado actual del conocimiento en Patagonia y Tierra del Fuego. Anales del Instituto de la Patagonia 18:157-177.

Nelson, M. 1991. The study or technological organization. En Archaeological Method and Theory, editado por M. Schiffer, vol. 3, pp. 57-100. University of Arizona Press, Tucson.

Núñez, L. y C. Santoro 1988. Cazadores de la Puna Seca y Salada del Área Centro Sur Andina (Norte de Chile). Estudios Atacameños 9:11-60.

Ratto, N. 2003. Estrategias de Caza y Propiedades del Registro Arqueológico en la Puna de Chaschuil (Departamento de Tinogasta, Catamarca). Tesis Doctoral. Facultad de Filosofía y Letras, Universidad de Buenos Aires, Buenos Aires.

Restifo, F. y R. Hoguin 2012. Risk and technological decisionmaking during the early to mid-Holocene transition: A comparative perspective in the Argentine Puna. Quaternary International 256:35-44.

Rivero, D. 2007. Los primeros pobladores de las Sierras Centrales de la Argentina. Las evidencias más antiguas del sitio "El Alto 3" (Dpto. de Punilla, Córdoba). Comechingonia Virtual 1:32-51.

Sampietro Vattuone, M.M. y L. Neder 2011. Quaternary landscape evolution and human occupation in norhwestern Argentina. Geological Society 352:37-47.
Serrano, A. 1968. El Precerámico en la República Argentina Países Vecinos. Publicaciones. Instituto de Antropología, Universidad Nacional de Córdoba, Córdoba.

Somonte, C. 2009. Tecnología Lítica en Espacios Persistentes de Amaicha del Valle (Tucumán). Tesis Doctoral. Facultad de Filosofía y Letras, Universidad de Buenos Aires, Buenos Aires.

Somonte, C. y C. Baied 2013. Edad mínima de exposición de superficies en canteras-taller: reflexiones en torno a las primeras dataciones mediante microlaminaciones del barniz de las rocas (VML) para el noroeste argentino. Chungara Revista de Antropología Chilena 45:427445 .

Strecker, M.R. 1987. Late Cenozoic Landscape in Santa María Valley, Northwestern Argentina. Tesis Doctoral. Cornell University, Cornell.

Tarragó, M. y M. de Lorenzi 1976. Arqueología de los valles Calchaquíes. Etnía 1:1-35.

Yacobaccio, H., P.S. Escola, F.X. Pereyra, M. Lazzari y M.D. Glascock 2004. Quest for ancient rout: Obsidian sourcing research in Northwestern Argentina. Journal of Archaeological Science 31:193204.

Weitzel, C. 2012. Cuentan los fragmentos. Clasificación y causas de fracturas de artefactos formatizados por talla. Intersecciones Antropología 13:43-55.

Weitzel, C. y M. Colombo 2006. ¿Qué hacemos con los fragmentos? Un experimento en fractura de artefactos líticos tallados. La Zaranda de Ideas 2:19-33.

Yacobaccio, H. 1991. Sistemas de Asentamiento de los Cazadoresrecolectores Tempranos de los Andes Centro-Sur. Tesis Doctoral. Facultad de Filosofía y Letras, Universidad de Buenos Aires, Buenos Aires.

\section{Notas}

1 El otro fechado disponible para el valle del Cajón (Catamarca) perteneciente a momentos de ocupación cazadorarecolectora, es el publicado por Cortés (2013), perteneciente a una mujer enterrada en un sector de cárcavas denominada "El Aumento", cuya datación es de $6.133 \pm 66$ a.p.
2 Debemos destacar que de los análisis tecno-tipológicos efectuados por Aschero et al. (2011) en los ejemplares de ICc7 y Camarones 14 se establece que algunos de los diseños en mandorla corresponderían a diseños mantenidos, ya sea por reactivación o por reversión , es decir cuando se gira a la pieza $180^{\circ}$ para cambiar ápices por base o viceversa. 
